\title{
Evidence that supports the prescription of low-carbohydrate high-fat diets: a narrative review
}

\author{
Timothy David Noakes, ${ }^{1}$ Johann Windt ${ }^{2,3}$
}

\begin{abstract}
- Additional material is published online only. To view please visit the journal online (http://dx.doi.org/10.1136/ bjsports-2016-096491).

${ }^{1}$ Department of Human Biology, University of Cape Town, Sports Science Institute of South Africa, Newlands, Cape Town, South Africa ${ }^{2}$ Department of Experimental Medicine, University of British Columbia, Vancouver, British Columbia, Canada

${ }^{3}$ Centre for Hip Health and Mobility, University of British Columbia, Vancouver, British Columbia, Canada
\end{abstract}

\section{Correspondence to} Professor Timothy David Noakes, Department of Human Biology, Division of Exercise Science and Sports Medicine, University of Cape Town, Sports Science Institute of South Africa,

Boundary Road, Newlands, Cape Town 7700,

South Africa;

timothy.noakes@uct.ac.za

Accepted 21 November 2016

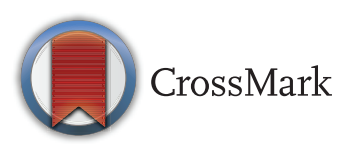

To cite: Noakes TD, Windt J. Br J Sports Med 2016;51:133-139.

\section{ABSTRACT}

Low-carbohydrate high-fat (LCHF) diets are a highly contentious current topic in nutrition. This narrative review aims to provide clinicians with a broad overview of the effects of LCHF diets on body weight, glycaemic control and cardiovascular risk factors while addressing some common concerns and misconceptions. Blood total cholesterol and LDL-cholesterol concentrations show a variable, highly individual response to LCHF diets, and should be monitored in patients adhering to this diet. In contrast, available evidence from clinical and preclinical studies indicates that LCHF diets consistently improve all other markers of cardiovascular risk - lowering elevated blood glucose, insulin, triglyceride, ApoB and saturated fat (especially palmitoleic acid) concentrations, reducing small dense LDL particle numbers, glycated haemoglobin $\left(\mathrm{HbA}_{1 \mathrm{c}}\right)$ levels, blood pressure and body weight while increasing low HDL-cholesterol concentrations and reversing non-alcoholic fatty liver disease (NAFLD). This particular combination of favourable modifications to all these risk factors is a benefit unique to LCHF diets. These effects are likely due in part to reduced hunger and decreased ad libitum calorie intake common to lowcarbohydrate diets, allied to a reduction in hyperinsulinaemia, and reversal of NAFLD. Although LCHF diets may not be suitable for everyone, available evidence shows this eating plan to be a safe and efficacious dietary option to be considered. LCHF diets may also be particularly beneficial in patients with atherogenic dyslipidaemia, insulin resistance, and the frequently associated NAFLD.

\section{INTRODUCTION}

Imagine a obese $\left(\mathrm{BMI}=32 \mathrm{~kg} / \mathrm{m}^{2}\right)$ woman aged 57 years with other evidence for insulin resistance (IR), including hyperinsulinaemia and impaired glucose tolerance together with atherogenic dyslipidaemia (AD) (triglyceride $(\mathrm{TG})=340 \mathrm{mg} / \mathrm{dL}(8.8 \mathrm{mmol} / \mathrm{L})$, HDL-cholesterol $(\mathrm{HDL}-\mathrm{C})=42.4 \mathrm{mg} / \mathrm{dL}(1.1 \mathrm{mmol} / \mathrm{L})$, LDL-cholesterol $(\mathrm{LDL}-\mathrm{C})=195 \mathrm{mg} / \mathrm{dL}(5.05 \mathrm{mmol} / \mathrm{L}))$ who enters her family physician's office. Frustrated with her poor health and progressive weight gain, on the advice of a friend, she has decided to begin a low-carbohydrate high-fat (LCHF) Atkins-type diet. How should her physician respond? What evidence does the physician require to make an informed decision?

LCHF diets have polarised the opinions of medical caregivers, especially since the publication of Dr Atkins' Diet Revolution in 1972. ${ }^{1}$ Some believe that these diets effectively treat type 2 diabetes mellitus (T2DM), obesity and metabolic syndrome. ${ }^{23}$ Others consider them to be simply a fad ${ }^{4}$ in conflict with current globally accepted dietary guidelines that advocate low-fat high-carbohydrate
(LFHC) diets to reduce the risk of cardiovascular disease. ${ }^{5}{ }^{6}$ Faced with such conflicting opinions, the clinician may be unsure how to advise this or other similar patients. Here, we provide an updated narrative review of the large body of published evidence describing the physiological effects, efficacy and safety of LCHF diets for the management, especially of this type of patient characterised by IR and $\mathrm{AD}$.

A number of systematic reviews have compared the effects of LCHF diets, traditional LFHC diets and other dietary strategies ${ }^{7-13}$ on body weight control and cardiovascular risk factors. Collectively, they establish that, for weight loss, LCHF diets are just as effective, if not more so, than LFHC diets. ${ }^{9}{ }^{14-16}$ They also highlight a number of significant changes to cardiovascular risk factors in participants adhering to LCHF diets. ${ }^{10} 14 \quad 17$ The strength of these reviews is their systematic research strategy and meta-analysis of data to answer specific research questions. However, this strength limits their relevance to their defined question, not allowing a broader overview of the evidence for metabolic, physiological and other effects of LCHF diets.

The aim of this review is not to argue whether LCHF diets are superior to other dietary strategies for any specific health outcome. Rather, we synthesise the evidence for the effects of LCHF diets on weight loss, glycaemic control, modification of cardiovascular risk factors as well as non-alcoholic fatty liver disease (NAFLD) and its associated AD. Further, we address common concerns sometimes presented as reasons why LCHF diets should not be prescribed to any patient. Through this process, we hope to provide clinicians with additional evidence to inform their clinical decision-making, better to understand the potential benefits of these eating plans for at least some patients.

\section{DEFINITIONS}

Though definitions of LCHF diets differ, the following three-tiered definition will be used in this paper. $^{2}$

- Moderate carbohydrate diet (26-45\% of daily kcal)

- LCHF diet $(<26 \%$ of total energy intake or $<130$ g CHO/day)

- Very LCHF (ketogenic) diet (20-50 g CHO/day or $<10 \%$ of daily kcal of $2000 \mathrm{kcal} /$ day diet)

Reduced carbohydrate diets are those that have carbohydrate intakes below the Dietary Guidelines for Americans (DGA) recommendations (of 45$65 \%$ of total energy intake). However, we define LCHF diets as those that restrict carbohydrate intake to $130 \mathrm{~g} /$ day or less. Very LCHF (ketogenic) 
diets may induce ketosis in some people. Though individual responses vary, ketosis usually occurs in people who restrict their carbohydrate intake to below $20-50 \mathrm{~g} /$ day with some degree of protein restriction.

Since the carbohydrate content of the diet is significantly reduced, the relative proportion of energy derived from protein and fat will increase. In practice, however, LCHF diets typically produce a reduction in hunger ${ }^{18}$ with the result that the individual's total caloric consumption will usually decrease on the LCHF diet, sometimes significantly. Therefore, even though the relative contribution of fat to dietary energy intake may increase, the absolute fat intake may not. As a result, the term 'high fat' diet may be misleading. Hence, the term lowcarbohydrate healthy fat is probably more appropriate.

\section{WHAT FOODS ARE PRESCRIBED ON THE LCHF DIET}

LCHF diets are defined by what is 'not' eaten, instead of what is eaten. Although the details may vary depending on the specific type of LCHF diets (Atkins, Banting, Paleo, South Beach, etc), in each of these examples, there is a consistent focus on eating unprocessed food, consisting primarily of cruciferous and green leafy vegetables, raw nuts and seeds, eggs, fish, unprocessed animal meats, dairy products and natural plant oils and fats from avocados, coconuts and olives.

LCHF diets, even if ketogenic, are not 'no' carbohydrate diets. Rather, all encourage a high intake of green leafy vegetables, cruciferous vegetables and other non-starchy vegetables with moderate intakes of berries. Table 1 provides a list of foods recommended on a 'Banting' diet, ${ }^{19}$ a popular LCHF eating plan. LCHF eating plans promote meals such as omelettes, salads and animal protein such as steak, salmon or chicken with vegetables. ${ }^{19}$

\section{LCHF DIETS AND WEIGHT LOSS}

Obesity is the fifth leading risk factor for premature mortality. ${ }^{20}$ The prescription of the LCHF diet as one strategy for weight loss has been known since at least $1860,{ }^{21}$ as this particular eating plan was promoted as the preferred treatment for obesity in Sir William Osler's textbook from the early 1900s. ${ }^{22}$ The publication of Dr Atkin's Diet Revolution in $1972^{1}$ later resurrected interest in the LCHF diet in the USA and elsewhere. Four decades later, numerous randomised clinical trials (RCTs) and systematic reviews now allow a critical evaluation of the safety and efficacy of LCHF diets for weight reduction. This information was not available to either Osler or Atkins, making a review of this new evidence particularly opportune now.

Repeatedly, LCHF diets have performed as well or better than LFHC diets for weight loss in overweight or obese

Table 1 'Green list': recommended foods on a Banting (low-carbohydrate high-fat) diet

\begin{tabular}{|c|c|c|c|c|}
\hline $\begin{array}{l}\text { Animal } \\
\text { protein }\end{array}$ & Dairy & Fats & $\begin{array}{l}\text { Nuts and } \\
\text { seeds }\end{array}$ & Vegetables \\
\hline $\begin{array}{l}\text { Eggs } \\
\text { Meats } \\
\text { Poultry } \\
\text { Game } \\
\text { Seafood }\end{array}$ & $\begin{array}{l}\text { Cottage } \\
\text { cheese } \\
\text { Cream } \\
\text { Full-cream } \\
\text { Greek } \\
\text { Yogurt } \\
\text { Cheeses }\end{array}$ & $\begin{array}{l}\text { Olive oil } \\
\text { Avocados } \\
\text { Coconut oil } \\
\text { Macadamia } \\
\text { nut oil }\end{array}$ & $\begin{array}{l}\text { Almonds } \\
\text { Flaxseeds } \\
\text { Macadamia } \\
\text { nuts } \\
\text { Pecans } \\
\text { Pine nuts }\end{array}$ & $\begin{array}{l}\text { All green leafy } \\
\text { vegetables, } \\
\text { cruciferous } \\
\text { vegetables or above } \\
\text { ground vegetables }\end{array}$ \\
\hline
\end{tabular}

adults. $^{9}{ }^{14-17}$ Bazzano et al' $\mathrm{s}^{23}$ recent 1-year trial randomised 148 obese men and women without T2DM or cardiovascular disease to an ad libitum LFHC $(<30 \%$ fat, $<7 \%$ saturated fat, $55 \%$ carbohydrates) or an LCHF ( $<40 \mathrm{~g}$ carbohydrates/day) diet. After 12 months, the LCHF diet group had lost significantly $(\mathrm{p}=0.002)$ more weight $(-5.3 \mathrm{~kg})$ than the LFHC group $(-1.8 \mathrm{~kg})$, and experienced a $1.3 \%$ decrease in $\%$ body fat compared with a $0.3 \%$ gain in the LFHC group. This equivalent or superior performance of LCHF diets over LFHC diets for weight loss has also been established in randomised trials in adolescents, ${ }^{24-26}$ and in adults with, ${ }^{27-29}$ or without ${ }^{30-35}$ T2DM. A recent reanalysis ('The universities of Stellenbosch/Cape Town low-carbohydrate diet review: Mistake or mischief? ${ }^{35 a}$ ) shows that lower carbohydrate diets outperform isoenergetic high carbohydrate 'balanced' diets for weight loss of the systematic analysis comparing weight loss and the response of other health markers with isocaloric high and moderate $(35 \%)$ carbohydrate $\operatorname{diets}^{7}$ found that weight loss was slightly but significantly greater on the moderate carbohydrate diet, even though the diets were isoenergetic.

The efficacy of LCHF diets extends beyond weight loss. In a 24-week trial of 84 patients with T2DM, Westman $e t a^{36}$ found that a ketogenic LCHF diet produced significantly greater weight loss than an energy-restricted $(500 \mathrm{kcal} /$ day below RMR), low glycaemic (GI) diet ( $-11.1 \mathrm{vs}-6.9 \mathrm{~kg})$. The ketogenic LCHF diet also significantly increased blood HDL-C concentrations and reduced blood $\mathrm{HbA}_{1 \mathrm{c}}$ values. Additionally, more patients on the LCHF diet were able to reduce or cease their use of diabetic medications.

The 1-year A to $\mathrm{Z}$ study ${ }^{37}$ randomised 311 overweight/obese premenopausal women to the Atkins $(<20 \mathrm{~g}$ carbohydrates/day induction, $<50 \mathrm{~g}$ carbohydrates/day maintenance, ad libitum energy intake), Zone (40\% carbohydrate, $30 \%$ protein, $30 \%$ fat, energy restricted), Ornish $(<10 \%$ fat, ad libitum) or LEARN $(55-60 \%$ carbohydrate, $10 \%$ saturated fat, energy restricted) diets. After 12 months, the mean weight loss in the LCHF Atkins group was $-4.7 \mathrm{~kg}$, compared with $-1.6 \mathrm{~kg}$ on the Zone Diet, $-2.2 \mathrm{~kg}$ on the Ornish and $-2.6 \mathrm{~kg}$ on the LEARN groups. Further, blood HDL-C and TG concentrations were significantly improved in the Atkins group compared with all other diet groups, at least initially.

Shai $e a^{38}$ randomised 322 moderately obese participants to an energy restricted Mediterranean diet (MED), energy-restricted LFHC diet or an ad libitum LCHF diet. The most significant weight loss occurred in the LCHF group at 6 months, even though this was the only diet eaten ad libitumthat is, it was not energy-restricted. At the end of the 24-month trial, weight loss was $-4.7 \mathrm{~kg}$ for LCHF, -4.4 for MED and $-2.9 \mathrm{~kg}$ for LFHC participants. Weight loss on the LCHF diet is greatest early in these trials when participants comply most rigorously to the carbohydrate restrictions, as also occurred at 6 months in the $\mathrm{A}$ to $\mathrm{Z}$ trial. ${ }^{37}$ Subsequent weight gain occurs as participants begin to ingest more carbohydrates daily, so-called 'carbohydrate creep', seen in the 6-12-month period in that trial and between months 6 and 24 in the study of Shai et al. ${ }^{38}$ Obviously, this reintroduction of greater carbohydrate ingestion increases energy intake with consequent weight regain. Thus, weight regain is not necessarily the fault of the LCHF diet; rather it is the consequence of its discontinuation.

This applies to all dietary interventions, where weight regain occurs with decreased adherence. Conversely, motivated freeliving individuals who maintain diet adherence, sometimes to address serious personal medical conditions, self-report weight losses an order of magnitude greater than the rather modest 
weight losses measured in clinical trials. LCHF diets are no exception, where some have reported effortless weight losses of greater than $-80 \mathrm{~kg}$ following adoption of the LCHF diet. ${ }^{39}$ Indeed, a recently reported low-cost lifestyle intervention study ${ }^{40}$ based on a high-fat diet recorded weight losses in excess of $12 \%$ in 372 participants; exceeding typical losses of 3-7\% in other well-funded studies in which the chosen diets were higher in carbohydrate.

In summary, while some studies show no difference in weight losses between LFHC and LCHF diets, ${ }^{78} 11$ others report that LCHF diets are more effective. ${ }^{9}{ }^{14-17} 35$ a Notably, all the tested diets are effective at inducing at least short-term weight loss, usually followed by some weight regain as adherence diminishes. However, LCHF diets clearly perform at least as well as do any other dietary approach, even in trials in which energy intake on the LCHF diet is unrestricted (ad libitum).

\section{Mechanisms for successful weight loss on the LCHF eating plan}

Two main mechanisms have been proposed to explain how LCHF diets produce weight loss, despite an increased consumption of energy-dense 'fatty' foods:

1. increased satiety, allowing a lower energy intake without hunger and

2. a specific metabolic advantage.

\section{Increased satiety allowing a lower energy intake without hunger}

A recent systematic review compared weight loss between participants on 'LCHF diets' and 'low fat balanced diets" ${ }^{7}$ but excluded all trials that were not isoenergetic. However, in doing so, they excluded trials that demonstrate the advantage of LCHF diets in producing greater satiety and a subsequently reduced energy intake. Indeed, this was the unique biological advantage that Banting, ${ }^{21}$ Ebstein $^{41}$ and Atkins ${ }^{1}$ all originally ascribed to the LCHF diet on the basis of their clinical observations. Although the original study did not find any differences in weight loss between the different diets, a reanalysis ${ }^{35 a}$ of the same data found a small but significantly great weight loss on the lower carbohydrate diet.

As an illustration, table 2 lists a collection of studies which show that participants on LCHF diets given unrestricted access to eating foods ad libitum do not necessarily consume more calories than participants assigned to LFHC diets, even when the latter are required consciously to 'energy restrict' their caloric intake according to their experimental design.

These results are supported by lower measures of perceived hunger in some participants eating LCHF diets. ${ }^{34}$ Greater satiety on LCHF diets in persons responding to the diet may result from a number of mechanisms: (1) some LCHF diets may have increased protein intake, which promotes satiety; ${ }^{43}$ (2) ketogenic LCHF diets may also suppress appetite, ${ }^{44}$ though the exact mechanisms remain uncertain; ${ }^{45}$ and (3) participants may experience fewer instances of rebound hypoglycaemia, a common cause of hunger in those eating high-carbohydrate foods, ${ }^{46}$ especially if they are IR. Regardless of the exact mechanism, it is notable that LCHF diets can achieve an energy deficit and subsequent weight loss with little hunger and without conscious energy restriction, as originally noted by Stock and Yudkin. ${ }^{18}$

\section{Postulated 'metabolic advantage' of LCHF diets}

The superior satiating effects of LCHF diets may not fully explain weight losses from LCHF diets. For example, some trials have shown greater weight loss for LCHF diets, despite higher energy intakes than prescribed LFHC diets. ${ }^{3} 253147$ Similarly, although some trials find no differences, ${ }^{48}$ some isoenergetic trials still find greater weight losses on LCHF diets. $^{33} \quad 35 a \quad 49$ Meta-analyses report similarly variable outcomes. $^{750}$

Although contentious, it has been suggested that LCHF diets may provide a metabolic 'advantage' favouring greater weight loss, despite the ingestion of an equal number of calories. This metabolic advantage could be attributed to a number of mechanisms, including: (1) increased thermogenic effects of protein intake, (2) greater protein turnover for gluconeogenesis and (3) loss of energy through excretion of ketones in sweat or urine. $^{5152}$

LCHF diets increase reliance on fat oxidation for energy production, especially during exercise, ${ }^{53} 54$ as shown by increased blood ketone concentrations and with reductions in respiratory quotient and blood insulin concentrations. ${ }^{53-55}$ This state of increased lipolysis with reduced lipogenesis contributes to a metabolic milieu theoretically favouring fat loss. This effect is dependent on reduced blood insulin concentrations, uniquely produced by the LCHF diet. However, this remains a contentious idea, with recent metabolic ward evidence suggesting that, at least in the short term (5 days), there is not a preferential fat-loss effect of LCHF diets. ${ }^{56}$

\section{LCHF DIETS IN THE MANAGEMENT OF T2DM}

T2DM is primarily a condition of IR, with persistent hyperglycaemia as a result of excessive hepatic glucose production $^{57}$ as its defining characteristic. Of all the macronutrients, carbohydrates cause the greatest and most prolonged increases in blood glucose and insulin concentrations. ${ }^{58}$ It is therefore no surprise

Table 2 Prescribed and documented energy intakes on a selection of low-carbohydrate high-fat and low-fat high-carbohydrate diets

\begin{tabular}{|c|c|c|c|c|c|}
\hline Author & $\begin{array}{l}\text { Prescribed energy } \\
\text { intake on LCHF diet }\end{array}$ & $\begin{array}{l}\text { Prescribed energy } \\
\text { restriction on LFHC diet }\end{array}$ & $\begin{array}{l}\text { Documented energy } \\
\text { intake on ad libitum } \\
\text { LCHF diet }\end{array}$ & $\begin{array}{l}\text { Documented energy } \\
\text { intake on energy-restricted } \\
\text { LFHC diet }\end{array}$ & $\begin{array}{l}\text { Mean weight } \\
\text { loss }(\mathrm{kg})\end{array}$ \\
\hline Brehm et $\left.a\right|^{31}$ & Ad libitum & $-500 \mathrm{kcal}$ based on Harris-Benedict equation & $\begin{array}{l}1608 \mathrm{kcal} \text { baseline } \\
1302 \mathrm{kcal} 6 \text { months }\end{array}$ & $\begin{array}{l}1707 \mathrm{kcal} \text { baseline } \\
1247 \mathrm{kcal} 6 \text { months }\end{array}$ & $\begin{array}{l}\mathrm{LC}=-8.5^{*} \\
\mathrm{LF}=-3.9\end{array}$ \\
\hline Samaha et $a l^{42}$ & Ad libitum & $-500 \mathrm{kcal}$ energy restriction & $\begin{array}{l}2090 \text { kcal baseline } \\
1630 \text { kcal } 6 \text { months }\end{array}$ & $\begin{array}{l}1848 \text { kcal baseline } \\
1576 \text { kcal } 6 \text { months }\end{array}$ & $\begin{array}{l}\mathrm{LC}=-5.8^{*} \\
\mathrm{LF}=-1.4\end{array}$ \\
\hline Yancy et $a \beta^{35}$ & Ad libitum & $-500-1000 \mathrm{kcal} /$ day energy restriction & $1461 \mathrm{kcal}$ & $1502 \mathrm{kcal}$ & $\begin{array}{l}\mathrm{LC}=-12.0^{*} \\
\mathrm{LF}=-6.5\end{array}$ \\
\hline Nickols-Richardson et $a^{34}$ & Ad libitum & 1500-1700 kcal/day limit & $\begin{array}{l}2025 \text { kcal baseline } \\
1420 \text { kcal } 6 \text { months }\end{array}$ & $\begin{array}{l}2340 \mathrm{kcal} \text { baseline } \\
1395 \mathrm{kcal} 6 \text { months }\end{array}$ & $\begin{array}{l}\mathrm{LC}=-6.4^{*} \\
\mathrm{LF}=-4.2\end{array}$ \\
\hline
\end{tabular}


that prior to the discovery of insulin, carbohydrate restriction, often associated with fasting or even starvation, was the eating plan prescribed for all diabetic patients regardless of type (1 or 2). ${ }^{59}$ Today, LCHF diets are again being discussed as a potential first-line treatment for T2DM. ${ }^{2} 6061$

In a 24-week trial, 363 overweight and obese patients chose according to their preference, to follow either a ketogenic LCHF diet or a 'low calorie, high nutritional value' diet. In the 102 patients with T2DM, weight loss was significantly greater $(-12.0 \%$ vs $-7.0 \%)$ and $\mathrm{HbA}_{1 \mathrm{c}}$ and fasting blood glucose concentrations decreased significantly more with the LCHF diet. ${ }^{62}$

A 3-month trial $^{27}$ randomised 34 prediabetic or T2DM patients to a calorie-restricted diet consistent with American Diabetes Association (ADA) guidelines or an ad libitum very LCHF diet. The very LCHF group showed a significant reduction $(6.6-6.0 \%)$ in $\mathrm{HbA}_{1 \mathrm{c}}$ values compared with unchanged values $(6.9 \%$ at baseline and follow-up) in the ADA group. This change in $\mathrm{HbA}_{1 \mathrm{c}}$ values indicated a strong effect size $(\mathrm{d}=-1.8)$, and occurred even though significantly more participants in the very low LCHF group decreased their use of diabetic medications. The very low LCHF group also lost more weight $(-5.5$ vs $-2.6 \mathrm{~kg}$ ). Similar results were seen in Westman et al's ${ }^{36} 24$-week trial also comparing a very low LCHF diet with a low GI diet. Participants on the very LCHF diet experienced significantly greater decreases in $\mathrm{HbA}_{1 \mathrm{c}}(-1.5 \%$ vs $-0.5 \%, \mathrm{p}=0.03)$, even though a greater percentage of patients $(95 \%$ vs $62 \%$ of low GI participants) reduced or stopped taking their diabetic medications.

The recent study of Tay et $a l^{63}$ randomised 115 obese adults with T2DM to either LCHF or LFHC diets for 1 year. Although both diets achieved substantial weight loss and reduced $\mathrm{HbA}_{1 \mathrm{c}}$ and fasting glucose concentrations, the LCHF diet produced greater improvements in blood glucose stability and superior reductions in diabetes medication requirements. In addition, the LCHF diet produced larger increases in HDL cholesterol concentrations and greater reductions in TG concentrations without changing total or LDL cholesterol concentrations. The recently reported lifestyle intervention trial ${ }^{40}$ which prescribed a high-fat diet for weight maintenance also produced these beneficial changes while LDL-cholesterol concentrations also fell substantially.

Weight loss on any diet improves glycaemic control, so it may be assumed that positive changes with an LCHF diet are attributable to concomitant weight loss. However, it should be noted that carbohydrate restriction positively influences glycaemic control even in the absence of weight loss. ${ }^{64} 65$

\section{LCHF DIETS AND CARDIOVASCULAR RISK FACTORS}

A common concern expressed by physicians, especially cardiologists, is that any increased dietary fat intake on the LCHF diet will increase the risk for the future development of cardiovascular disease. This conviction stems largely from Ancel Keys' original seven countries study, ${ }^{66}$ and the subsequent development of the LFHC dietary guidelines to prevent cardiovascular disease. ${ }^{67} 68$ However, evidence from numerous RCTs indicate that LCHF diets consistently produce more favourable changes in many measures of cardiovascular risk than do LFHC diets. This applies especially in persons with IR, T2DM, AD and NAFLD.

Examination of blood lipid concentrations in RCTs reveals that LCHF diets have a potent effect in lowering blood TG concentrations, ${ }^{69}$ to a significantly greater degree than do LFHC diets. $^{3} 327071$ Blood ApoB concentrations-an indirect measure of lipoprotein particle numbers and also a risk predictor for coronary artery disease-also decrease more on LCHF than on the LFHC diet. ${ }^{3} 72$

Furthermore, of all dietary interventions, none increase HDL-C concentrations as effectively as do LCHF diets, which outperform LFHC, $^{23}{ }^{35}{ }^{70}$ low glycaemic index, ${ }^{73}$ Zone, LEARN, Ornish ${ }^{37}$ and in some cases, MEDs. ${ }^{38}$ After a 1-year isocaloric intervention comparing a very LCHF with an LFHC diet, Tay et $a l^{70}$ found greater decreases in blood TG concentrations $(-0.58$ vs $-0.22 \mathrm{mmol} / \mathrm{L})$ and greater increases in HDL-C concentrations $(+0.30 \mathrm{vs}+0.07 \mathrm{mmol} / \mathrm{L})$ in participants on the LCHF diet, despite similar weight losses. Since a high TG to HDL-C ratio predicts extensive coronary artery disease, ${ }^{74}$ and is common in patients with IR and NAFLD, the long-term benefits of this unique capacity of LCHF diets markedly to alter both markers should not be underestimated.

On the other hand, a common argument against the LCHF eating plan is the variable LDL-C response to a relative or absolute increase in dietary fat intake. Many trials demonstrate a decrease or insignificant change in LDL-C concentrations in response to the LCHF diet, ${ }^{75} 76$ but some report a more marked increase. ${ }^{77}$ Although HDL-C concentrations increased and TG concentrations decreased significantly more in participants on the LCHF diet in the study of Tay et al, ${ }^{70}$ LDL-C $(+0.6$ vs $+0.1 \mathrm{mmol} / \mathrm{L})$ and total cholesterol $(+0.7$ vs $+0.1 \mathrm{mmol} / \mathrm{L})$ concentrations increased significantly more in participants in that group.

Systematic reviews confirm these findings. Table 3 shows that LCHF diets significantly increase HDL-C concentrations, decrease TG concentrations and weight, without any significant effects on LDL-C concentrations. ${ }^{14} \mathrm{Hu}$ et al ${ }^{11}$ also documented greater improvements in TG and HDL-C concentrations in response to LCHF compared with LFHC diets, but total cholesterol and LDL-C concentrations fell significantly more in participants on the LFHC diets.

When assessing the relevance of any increase in total cholesterol concentrations produced by the LCHF diet, the other beneficial metabolic effects specific to LCHF diets must be considered (table 3). ${ }^{76} 78{ }^{79}$ First, the LCHF-induced increase in HDL-C concentrations is considered protective against cardiovascular disease. ${ }^{80}$ In contrast, LFHC diets do not produce an equivalent HDL-C-raising effect and may in fact cause HDL-C concentrations to fall, ${ }^{72}$ a potentially detrimental effect.

Second, considering changes in LDL-C concentrations in isolation fail to acknowledge the importance of changes in particle subfraction distributions, specifically the atherogenic effects of

Table 3 The effects of low-carbohydrate high-fat diets on some cardiovascular risk factors

\begin{tabular}{llc}
\hline Marker & Effect & Mean change $(95 \% \mathrm{Cl})$ \\
\hline Weight $(\mathrm{kg})$ & Decreases & $-7.04(-7.20$ to -6.98$)$ \\
$\mathrm{BMI}\left(\mathrm{kg} / \mathrm{m}^{2}\right)$ & Decreases & $-2.09(-2.15$ to -2.04$)$ \\
Abdominal circumference $(\mathrm{cm})$ & Decreases & $-5.74(-6.07$ to -5.41$)$ \\
Systolic blood pressure $(\mathrm{mm} \mathrm{Hg})$ & Decreases & $-4.80(-5.53$ to -4.29$)$ \\
Diastolic blood pressure $(\mathrm{mm} \mathrm{Hg})$ & Decreases & $-3.10(-3.45$ to -2.74$)$ \\
$\mathrm{HDL}$ cholesterol $(\mathrm{mg} / \mathrm{dL})$ & Increases & $+1.73(1.44$ to 2.01$)$ \\
$\mathrm{LDL}$ cholesterol $(\mathrm{mg} / \mathrm{dL})$ & No significant & $-0.48(-1.53$ to 0.57$)$ \\
& change $($ variable) & \\
Plasma triglycerides $(\mathrm{mg} / \mathrm{dL})$ & Decreases & $-29.71(-31.99$ to -27.44$)$ \\
Glycated haemoglobin $(\%)$ & Decreases & $-0.21(-0.24$ to -0.18$)$ \\
Plasma insulin $(\mu \mathrm{IU} / \mathrm{mL})$ & Decreases & $-2.24(-2.65$ to -1.82$)$ \\
\hline \multicolumn{2}{c}{ Adapted, with permission, from Santos et al. ${ }^{14}$} &
\end{tabular}


small, dense LDL particles, compared with the relatively neutral effect of large, buoyant LDL particles. ${ }^{81}$

As serum TG concentrations are inversely related to the number of small dense LDL particles, ${ }^{82} 83$ the LCHF-induced decrease in blood TG concentrations indicates a less atherogenic distribution of these LDL particle subfractions. Indeed, LCHF diets consistently reduce the proportion of small, dense LDL particles while increasing the number of large, buoyant LDL particles. ${ }^{3} 3072758485$

Third, an apparent LDL-C-raising effect of the LCHF diet may be an artefact if LDL-C concentrations are predicted from measurements of total cholesterol, HDL-C and TG concentrations using the Friedewald equation. Even when all other measurements are unchanged, that equation will predict an increase in (unmeasured) LDL-C concentrations whenever blood TG concentrations fall, as happens in persons eating LCHF diets. Indeed, LDL-C concentrations predicted by the Friedewald equation becoming increasingly inaccurate at low blood TG concentrations, ${ }^{86}$ a typical response in persons eating the LCHF diet.

Fourth, the biological significance of these relatively small increases in LDL-C is unknown in persons eating LCHF diets and in whom there will be associated increases in LDL particle size distributions and reductions in harmful blood saturated fat concentrations, ${ }^{72} 87$ as well as other positive biological changes, including reduced ApoB concentrations, ${ }^{3}{ }^{72}$ improvements in flow-mediated arteriolar dilation, ${ }^{71}$ decreased inflammatory biomarkers, ${ }^{49}$ lower systolic and diastolic blood pressures, ${ }^{3}$ improved glycaemic control with reduced $\mathrm{HbA}_{1 \mathrm{c}}$, plasma glucose and insulin concentrations ${ }^{14}$ and preferential weight loss from the abdominal viscera indicating a greater reduction in visceral fat, including liver fat. All these changes in surrogate measures would be expected to reduce cardiovascular risk substantially. ${ }^{3} 47$

Indeed, another unique effect of the LCHF diet is to reverse NAFLD, particularly in those with IR and AD.

Nonetheless, the variability in LDL-C response to the CHF diet must be considered and markers of IR and AD should be monitored in patients who adopt this eating pattern.

\section{NAFLD, AD AND LCHF}

Cardiovascular disease is the leading cause of death in NAFLD, ${ }^{88}$ a condition causing elevated TG and low HDL-C concentrations with overproduction of very-low density lipoproteins and impaired clearance of TG-rich lipoproteins. ${ }^{89} 90$ Hepatic IR is also increased in persons with fatty $\operatorname{liver}^{91}$ as shown by inadequate suppression of hepatic glucose production by insulin in NAFLD. ${ }^{92}$

Recently, Bril et al ${ }^{91}$ have shown that NAFLD with IR is the cause of the $\mathrm{AD}$ characterised by all these features, including increased small dense LDL particle numbers (Pattern B).

Since NAFLD is caused by excessive carbohydrate, especially fructose intake, ${ }^{93-95}$ the finding that a carbohydrate-restricted LCHF diet can reverse AD (previous section) is more readily explained. The LCHF diet reverses the NAFLD and hence the $\mathrm{AD}$ that it causes.

In contrast, stepwise increases in carbohydrate intake 'is associated with incremental increases in the proportion of plasma palmitoleic acid, which may be signalling impaired metabolism of carbohydrate, even under conditions of negative energy balance and significant weight loss. These findings contradict the perspective that dietary saturated fat per se is harmful, and underscore the importance of considering the level of dietary carbohydrate that accompanies saturated fat consumption, ${ }^{87}$
In summary, while the response of blood LDL-C concentrations to LCHF diets may be variable, rising in some, simultaneous changes in many other blood markers suggest that this eating plan enhances cardiovascular health. Specifically, patients with high TG to HDL-C ratios and NAFLD, all of which are common in IR individuals eating LFHC diets, are more likely to benefit from the LCHF diet. Indeed, a recent lifestyle intervention trial reduced the prevalence of metabolic syndrome from $58 \%$ to $19 \%$ among obese and overweight patients treated with LCHF for as little as $3-8$ months, indicating how rapidly carbohydrate restriction can improve health in those with IR. ${ }^{40}$

\section{ADDRESSING COMMON MISCONCEPTIONS}

We next address some of the common concerns and misconceptions that are frequently raised by medical colleagues who are hesitant to prescribe LCHF diets for their patients.

\section{Is not ketosis a dangerous physiological state?}

A common error is to confuse nutritional ketosis with diabetic ketoacidosis. While the latter is life-threatening, nutritional ketosis is a normal physiological response to dietary carbohydrate restriction, in which the body alters its primary fuel utilisation from carbohydrates to fat. This change spares blood glucose for use particularly by the brain which has an obligatory glucose requirement of about $25 \mathrm{~g} /$ day ${ }^{96}$ when using alternative fuels including ketones or lactate in fat-adapted persons. ${ }^{54}$ Carbohydrate restriction increases the production of ketone bodies (acetoacetate, $\beta$-hydroxybuterate and acetone) by the liver. ${ }^{97}$ Ketosis occurs in the neonatal period ${ }^{98}$ during fasting and pregnancy, and in response to carbohydrate restriction. ${ }^{99}$ In adults consuming a 'normal' diet, blood ketone body concentrations vary between 0.1 and $0.3 \mathrm{mmol} / \mathrm{L}$. In nutritional ketosis, the levels may rise to over $1 \mathrm{mmol} / \mathrm{L}$, and maximally up to $7-$ $8 \mathrm{mmol} / \mathrm{L}$ but without an acidosis. In contrast, in diabetic ketoacidosis, blood ketone body concentrations usually exceed $25 \mathrm{mmol} / \mathrm{L}$ and blood $\mathrm{pH}$ decreases below 7.3. ${ }^{97}$

Existing evidence shows that not only is nutritional ketosis safe, but is also beneficial to many patients. ${ }^{76}$ Potential therapeutic uses for nutritional ketosis that have been suggested include the management of cancer, acne, polycystic ovarian syndrome and neurological diseases, including Alzheimer's disease. ${ }^{97}$ More recent evidence suggest that ketones including those ingested orally during exercise may produce beneficial metabolic effects ${ }^{100}$ and enhance athletic performance. ${ }^{101}$

\section{The dangers of high intakes of fat, saturated fat and protein}

As LCHF diets promote an increased relative or absolute energy intake from fats and proteins, concerns are often expressed about the potential dangers of the increased consumption of these macronutrients.

As first demonstrated in $1970,{ }^{18}$ and repeatedly since, ${ }^{29} 3749102$ a reduction in dietary carbohydrate intake does not necessarily cause a concomitant increase in total fat and protein intakes. Though the proportional amounts of energy supplied from fat and protein must increase, the absolute amounts often remain very similar, as total energy intake often decreases on LCHF diets. Nevertheless, it is this absolute or relative increase in fat intake that causes the greatest anxiety among medical colleagues.

The diet heart hypothesis based largely on Ancel Keys' original Seven Countries Study ${ }^{66}$ posits that saturated fat intake is the direct cause of coronary atherosclerosis. However, this theory is not supported by either the historical evidence or by 
more recent epidemiological data, ${ }^{103-113}$ which finds no association between saturated fat intake and all-cause mortality or progression of coronary atherosclerosis. ${ }^{114}$ Instead, higher fat intakes have been associated with lower rates of ischaemic stroke in men. ${ }^{115}$ Indeed, a continued decline in coronary mortality in the Japanese is associated with increasing blood cholesterol concentrations ${ }^{116}$ and increased fat intakes. ${ }^{117}$ Similarly, higher blood cholesterol concentrations are not associated with increased mortality after age 60. Given the sometimes dramatic improvements in coronary risk factors on the LCHF diet, ${ }^{39} 407679$ the fear of ill health effects from the increased (saturated) fat intake on the LCHF diet would appear to be groundless.

Instead, concerns may be expressed about the claimed benefits of replacing saturated fats with dietary polyunsaturated fats as these claims may be unproven ${ }^{118-122}$ and the effect of this substitution may even be harmful. ${ }^{122}{ }^{123}$ Rather epidemiological studies showing either a weak ${ }^{124}{ }^{125}$ or no ${ }^{126}$ association between the intake of red meat, especially processed red meat and an increased colon cancer risk have raised concerns. However, there is no evidence that the intake of moderate amounts of red meat has detrimental effects on conventional coronary risk factors. $^{127128}$

As with fat intake, total protein intake does not necessarily increase on an LCHF diet. Further, many LCHF diets are not high in protein; instead, they are relatively or absolutely high in fat. Regardless, no negative renal effects of an increased protein intake have been described in those with normal kidney function, ${ }^{129} 130$ including obese adults with T2DM with no pre-existing kidney disease. ${ }^{131}$ However, patients with renal dysfunction could theoretically be at risk of the hypertensive effects associated with higher protein intakes and warrant additional consideration. ${ }^{97}$ Finally, it should be noted that T2DM is the disease most responsible for renal failure and LCHF diets are an effective dietary strategy for controlling and preventing T2DM. ${ }^{260}$

\section{LCHF diets produce other dangerous effects}

Headache, fatigue and muscle cramping are potential side effects of very LCHF diets. However, these symptoms may be especially prevalent only in the period of adaptation to the diet, after which most subside. Some recommend that additional sodium should be ingested to minimise side effects, since excretion of water and sodium are increased on these diets. ${ }^{132}$ Nevertheless, it is advisable to monitor patients when they begin the LCHF diet and to explain that these side effects are almost always transient.

\section{Lack of nutrient density}

Nutrient density is primarily dependent on food quality, not purely on macronutrient composition. Therefore, it is possible to eat a nutrient-poor diet with any macronutrient composition. However, an LCHF diet that focuses on unrefined food from vegetables, meat, dairy and seeds/nuts provides a diet that is nutrient-dense, supplying all the essential nutrients. A large online survey of LCHF dieters found that most replaced traditional, refined nutrient-poor carbohydrate sources such as bread and pasta with an increased green leafy vegetable consumption, producing an improvement in nutrient density. ${ }^{133}$

\section{Weight loss on LCHF diets occurs via increased water loss}

Some suggest that the weight loss on LCHF diets is the result mainly of water loss. Indeed, increased diuresis accounts for some of the weight loss experienced in the first weeks of carbohydrate restriction. ${ }^{134}$ However, measurements of body composition by DEXA analysis clearly indicate that long-term weight loss on the LCHF diet is predominantly the result of the loss of fat mass with some loss of fat-free mass. ${ }^{3}$ Certainly, weight losses of $10 \mathrm{~kg}$ or more, seen in trials ${ }^{40 \quad 6276}$ and common in self-reports, ${ }^{39}$ cannot be due to water loss alone.

\section{The LCHF diet is unsustainable}

Trials show that adherence to LCHF and LFHC diets are similar, ${ }^{24} 2737$ while a recent systematic review found a higher attrition rate from LFHC than from LCHF diets. ${ }^{12}$ Therefore, it appears that patients find it no more difficult to adhere to an LCHF diet than any other dietary strategy. In fact, due to their unique capacity to reduce hunger, ${ }^{34}$ some patients may find LCHF diets to be more easily sustainable than LFHC diets which require conscious calorie restriction. Importantly, longterm adherence (6 months to $>1$ year $)^{76}$ to the LCHF has not identified any evidence of harm.

\section{LIMITATIONS OF THIS REVIEW}

Separating the specific effects of carbohydrate restriction from the effects of other components of the LCHF diet is challenging. Individuals adopting the LCHF diet do not just change the macronutrient composition of their diets but may improve the quality of food they eat, moving from processed and refined foods to green leafy vegetables, nuts, seeds and lean meats. Further, an ad libitum LCHF diet is often accompanied by a decreased calorie intake and subsequent weight loss. Collectively, at least some (though not all) of the benefits of the LCHF diet could stem from the often large weight losses typically produced by this diet. Therefore, at least some of the beneficial changes reported here for the LCHF diet would also be experienced by patients prepared to adhere to any calorie-restricted diet.

Though writing a narrative review allows a broad overview of many aspects of LCHF diets, it is impossible to cover every aspect of the diet or every relevant study. We have opted, where possible, to focus on human trials, as well as systematic reviews of these trials, acknowledging there are important areas of epidemiology, biochemistry, psychology, genomics and more that could not be included.

\section{SUMMARY AND CLINICAL CONSIDERATIONS}

One diet does not suit the individual metabolic profiles of everyone. Significant weight loss has been documented in trials comparing a variety of different dietary plans, with all diets performing better than no intervention (controls). ${ }^{8}$ In all cases, optimal nutrition should emphasise high nutrient density while properly managing energy balance. As discussed in this review, LCHF diets accomplish these two objectives effectively-controlling energy balance through increased satiety and reduced ad libitum energy intake while encouraging the ingestion of a nutrient-dense diet by replacing refined, nutrient-poor processed foods with nutrient-dense, natural foods. Further, the diet encourages weight loss and unique metabolic changes including marked improvements in glycaemic control and in plasma TG, HDL-C, ApoB and saturated fat concentrations, with reductions in the number of small dense LDL particles that are considered to be especially atherogenic. This unique effect is in part due to the reversal of NAFLD by carbohydrate restriction.

While the complex details of individual responses to many different dietary interventions still need to be explored, clinicians can be reassured that LCHF diets are proven to be a safe and efficacious strategy for weight loss and improved health outcomes for many patients, but especially for those with IR, the metabolic 
syndrome ${ }^{40} \mathrm{AD}$ and NAFLD. Thus, LCHF diets may be the ideal choice for patients who have struggled to lose weight on the traditional LFHC diets; for those with IR, including hyperinsulinaemia, T2DM and NAFLD; and for those with AD characterised by high blood TG and low HDL-C concentrations and increased numbers of small dense LDL particles (Pattern B).

In practice, beneficial responses to any diet are entirely dependent on the degree of patients' adherence, so an LCHF diet is only appropriate for those patients motivated to comply. In these cases, clinicians can expect positive changes in a number of cardiovascular risk factors, glycaemic control and body composition. ${ }^{40}$ Simultaneously, they should monitor individual LDL-C responses, and encourage a continued emphasis on nutrient-rich choices, avoiding ultra-processed foods. Thus, far from being a dietary fad, but not necessarily for everyone, LCHF diets present a sensible dietary option for weight loss and health improvement in certain patients, especially those characterised by IR, AD and NAFLD.

\section{What are the findings?}

- Low-carbohydrate high-fat (LCHF) diets are at least as effective as other dietary strategies for reducing body weight, with the additional advantage of increased satiety and spontaneous reduction in energy intake.

- LCHF diets are an effective dietary strategy to improve glycaemic control and reduce hyperinsulinaemia in type 2 diabetes mellitus and in otherwise healthy patients with insulin resistance.

- LCHF diets have unique effects on blood lipid concentrations and cardiovascular risk factors, characterised by decreased blood TG, ApoB and saturated fat concentrations, reduced small LDL particle numbers and increased HDL-C concentrations. The effect on LDL-C concentrations is variable.

\section{How might it impact on clinical practice in the future?}

A growing understanding that obesity/hypertension/T2DM/nonalcoholic fatty liver disease/atherogenic dyslipidemia and the metabolic syndrome may all be substantially influenced by a single over-riding environmental factor-a high carbohydrate diet, acting on a single metabolic state, insulin resistance-will revolutionise the medical and dietary management of these conditions over the next decade. From our analysis, the LCHF eating plan should become the default medical management approach for all these conditions.

\section{Twitter Follow Tim Noakes @ProfTimNoakes}

Funding JW was funded through a graduate award by the Canadian Institutes of Health Research, as well as through the Michael Smith Foreign Study Supplement.

Competing interests TDN is the author of the books Lore of Running and Waterlogged and coauthor of Challenging Beliefs, The Real Meal Revolution and Raising Superheroes. TDN has donated the rights to the royalties from the sale of Real Meal Revolution and Raising Superheroes to The Noakes Foundation of which he is the Chairman and which funds research of insulin resistance, diabetes and nutrition as directed by its Board of Directors. Money from the sale of other books is donated to the Tim and Marilyn Noakes Sports Science Research Trust which funds the salary of a senior researcher at the University of Cape Town, South Africa (research focuses on the study of skeletal muscle in African mammals with some overlap to the study of type 2 diabetes in carnivorous mammals and the effects of (scavenged) sugar consumption on free-living (wild) baboons).

Provenance and peer review Not commissioned, externally peer reviewed.

\section{REFERENCES}

1 Atkins RC. Dr Atkins diet revolution. 1st edn. New York: David McKay Company, 1972:1-310.

2 Feinman RD, Pogozelski WK, Astrup A, et al. Dietary carbohydrate restriction as the first approach in diabetes management: critical review and evidence base. Nutrition 2015;31:1-13.

3 Volek JS, Phinney SD, Forsythe CE, et al. Carbohydrate restriction has a more favorable impact on the metabolic syndrome than a low fat diet. Lipids 2009;44:297-309.

4 Moyad MA. Fad diets and obesity — Part III: a rapid review of some of the more popular low-carbohydrate diets. Urol Nurs 2004:24:442-5.

5 Blackburn GL, Phillips JC, Morreale S. Physician's guide to popular low-carbohydrate weight-loss diets. Cleve Clin J Med 2001;68:761, 765-6, 768-9, 773-4.

6 Smith SR. A look at the low-carbohydrate diet. N Engl J Med 2009;361:2286-8.

7 Naude CE, Schoonees A, Senekal M, et al. Low carbohydrate versus isoenergetic balanced diets for reducing weight and cardiovascular risk: a systematic review and meta-analysis. PLOS ONE 2014;9:e100652.

8 Johnston BC, Kanters S, Bandayrel K, et al. Comparison of weight loss among named diet programs in overweight and obese adults: a meta-analysis. JAMA 2014;312:923-33

9 Bueno NB, De Melo IS, De Oliveira SL, et al. Very-low-carbohydrate ketogenic diet v. low-fat diet for long-term weight loss: a meta-analysis of randomised controlled trials. Br J Nutr 2013;110:1178-87.

10 Ajala O, English P, Pinkney J. Systematic review and meta-analysis of different dietary approaches to the management of type 2 diabetes. Am I Clin Nutr 2013;97:505-16.

11 Hu T, Mills KT, Yao L, et al. Effects of low-carbohydrate diets versus low-fat diets on metabolic risk factors: a meta-analysis of randomized controlled clinical trials. Am J Epidemiol 2012;176(Suppl 7):S44-54.

12 Hession M, Rolland C, Kulkarni U, et al. Systematic review of randomized controlled trials of low-carbohydrate vs. low-fat/low-calorie diets in the management of obesity and its comorbidities. Obes Rev 2009;10:36-50.

13 Nordmann AJ, Nordmann A, Briel M, et al. Effects of low-carbohydrate vs low-fat diets on weight loss and cardiovascular risk factors: a meta-analysis of randomized controlled trials. Arch Intern Med 2006;166:285-93.

14 Santos FL, Esteves SS, Da Costa PA, et al. Systematic review and meta-analysis of clinical trials of the effects of low carbohydrate diets on cardiovascular risk factors. Obes Rev 2012;13:1048-66.

15 Tobias DK, Chen M, Manson JE, et al. Effect of low-fat diet interventions versus other diet interventions on long-term weight change in adults: a systematic review and meta-analysis. Lancet Diabetes Endocrinol 2015;3:968-79.

16 Sackner-Bernstein J, Kanter D, Kaul S. Dietary intervention for overweight and obese adults: comparison of low-carbohydrate and low-fat diets. A meta-analysis. PLOS ONE 2015;10:e0139817.

17 Mansoor N, Vinknes KJ, Veierod MB, et al. Effects of low-carbohydrate diets $\mathrm{V}$. low-fat diets on body weight and cardiovascular risk factors: a meta-analysis of randomised controlled trials. Br J Nutr 2016;115:466-79.

18 Stock AL, Yudkin J. Nutrient intake of subjects on low carbohydrate diet used in treatment of obesity. Am J Clin Nutr 1970;23:948-52.

19 Noakes TD, Creed SA, Proudfoot J, et al. The real meal revolution. 2nd edn. Cape Town: Quivertree Publications, 2013:1-298.

20 World Health Organization. Global health risks: mortality and burden of disease attributable to selected major risks. World Health Organization, 2009:1-70.

21 Banting W. Letter on corpulence addressed to the public. 3rd edn. San Francisco: A. Roman \& Co., 1865:1-64.

22 Osler W. The principles and practice of medicine. New York: D. Appleton and Company, 1978:2-1079.

23 Bazzano LA, Hu T, Reynolds K, et al. Effects of low-carbohydrate and low-fat diets: a randomized trial. Ann Intern Med 2014;161:309-18.

24 Krebs NF, Gao D, Gralla J, et al. Efficacy and safety of a high protein, low carbohydrate diet for weight loss in severely obese adolescents. J Pediatr 2010;157:252-8.

25 Sondike SB, Copperman N, Jacobson MS. Effects of a low-carbohydrate diet on weight loss and cardiovascular risk factor in overweight adolescents. J Pediatr 2003;142:253-8.

26 Partsalaki I, Karvela A, Spiliotis BE. Metabolic impact of a ketogenic diet compared to a hypocaloric diet in obese children and adolescents. J Pediatr Endocrinol Metab 2012;25:697-704.

27 Daly ME, Paisey R, Paisey R, et al. Short-term effects of severe dietary carbohydrate-restriction advice in Type 2 diabetes-a randomized controlled trial. Diabet Med 2006;23:15-20. 
28 Dyson PA, Beatty S, Matthews DR. A low-carbohydrate diet is more effective in reducing body weight than healthy eating in both diabetic and non-diabetic subjects. Diabet Med 2007;24:1430-5.

29 Saslow LR, Kim S, Daubenmier JJ, et al. A randomized pilot trial of a moderate carbohydrate diet compared to a very low carbohydrate diet in overweight or obese individuals with type 2 diabetes mellitus or prediabetes. PLOS ONE 2014;9: e91027.

30 Aude YW, Agatston AS, Lopez-Jimenez F, et al. The national cholesterol education program diet vs a diet lower in carbohydrates and higher in protein and monounsaturated fat: a randomized trial. Arch Intern Med 2004;164:2141-6.

31 Brehm BJ, Seeley RJ, Daniels SR, et al. A randomized trial comparing a very low carbohydrate diet and a calorie-restricted low fat diet on body weight and cardiovascular risk factors in healthy women. J Clin Endocrinol Metab 2003;88:1617-23.

32 Foster GD, Wyatt HR, Hill JO, et al. A randomized trial of a low-carbohydrate diet for obesity. N Engl J Med 2003;348:2082-90.

33 Halyburton AK, Brinkworth GD, Wilson CJ, et al. Low- and high-carbohydrate weight-loss diets have similar effects on mood but not cognitive performance. Am J Clin Nutr 2007;86:580-7.

34 Nickols-Richardson SM, Coleman MD, Volpe JJ, et al. Perceived hunger is lower and weight loss is greater in overweight premenopausal women consuming a low-carbohydrate/high-protein vs high-carbohydrate/low-fat diet. J Am Diet Assoc 2005; 105:1433-7.

35 Yancy WS Jr, Olsen MK, Guyton JR, et al. A low-carbohydrate, ketogenic diet versus a low-fat diet to treat obesity and hyperlipidemia: a randomized, controlled trial. Ann Intern Med 2004;140:769-77.

35a Harcombe Z, Noakes T. The universities of Stellenbosch/Cape Town lowcarbohydrate diet review: Mistake or mischief? SAMJ 2016;106:1179-82.

36 Westman EC, Yancy WS Jr, Mavropoulos JC, et al. The effect of a low-carbohydrate, ketogenic diet versus a low-glycemic index diet on glycemic control in type 2 diabetes mellitus. Nutr Metab (Lond) 2008;5:36.

37 Gardner CD, Kiazand A, Alhassan S, et al. Comparison of the Atkins, Zone, Ornish, and LEARN diets for change in weight and related risk factors among overweight premenopausal women: the A to Z Weight Loss Study: a randomized trial. JAMA 2007;297:969-77.

38 Shai I, Schwarzfuchs D, Henkin Y, et al. Weight loss with a low-carbohydrate, Mediterranean, or low-fat diet. N Engl J Med 2008;359:229-41.

39 Noakes TD. Low-carbohydrate and high-fat intake can manage obesity and associated conditions: occasional survey. S Afr Med J 2013;103:826-30.

40 Mark S, Du TS, Noakes TD, et al. A successful lifestyle intervention model replicated in diverse clinical settings. S Afr Med J 2016;106:763-6.

41 Ebstein W. Fettleibigkeit (Corpulenz). Wiesbaden: J F Bergmann, 1883:1-54.

42 Samaha FF, Iqbal N, Seshadri $P$, et al. A low-carbohydrate as compared with a low-fat diet in severe obesity. N Engl J Med 2003;348:2074-81.

43 Weigle DS, Breen PA, Matthys CC, et al. A high-protein diet induces sustained reductions in appetite, ad libitum caloric intake, and body weight despite compensatory changes in diurnal plasma leptin and ghrelin concentrations. Am J Clin Nutr 2005;82:41-8.

44 Johnstone AM, Horgan GW, Murison SD, et al. Effects of a high-protein ketogenic diet on hunger, appetite, and weight loss in obese men feeding ad libitum. Am J Clin Nutr 2008:87:44-55.

45 Paoli A, Bosco G, Camporesi EM, et al. Ketosis, ketogenic diet and food intake control: a complex relationship. Front Psychol 2015;6:27.

46 Melanson KJ, Westerterp-Plantenga MS, Saris WH, et al. Blood glucose patterns and appetite in time-blinded humans: carbohydrate versus fat. Am J Physiol 1999;277:R337-45.

47 Volek JS, Sharman MJ, Gomez AL, et al. Comparison of a very low-carbohydrate and low-fat diet on fasting lipids, LDL subclasses, insulin resistance, and postprandial lipemic responses in overweight women. J Am Coll Nutr 2004;23:177-84

48 Meckling KA, O'Sullivan C, Saari D. Comparison of a low-fat diet to a low-carbohydrate diet on weight loss, body composition, and risk factors for diabetes and cardiovascular disease in free-living, overweight men and women. J Clin Endocrinol Metab 2004;89:2717-23.

49 Forsythe CE, Phinney SD, Fernandez ML, et al. Comparison of low fat and low carbohydrate diets on circulating fatty acid composition and markers of inflammation. Lipids 2008;43:65-77.

50 Krieger JW, Sitren HS, Daniels MJ, et al. Effects of variation in protein and carbohydrate intake on body mass and composition during energy restriction: a meta-regression 1. Am J Clin Nutr 2006;83:260-74.

51 Feinman RD, Fine EJ. Thermodynamics and metabolic advantage of weight loss diets. Metab Syndr Relat Disord 2003;1:209-19.

52 Feinman RD, Fine EJ. 'A calorie is a calorie' violates the second law of thermodynamics. Nutr J 2004;3:9.

53 Volek JS, Freidenreich DJ, Saenz C, et al. Metabolic characteristics of keto-adapted ultra-endurance runners. Metab Clin Exp 2016;65:100-10.
54 Webster CC, Noakes TD, Chacko SK, et al. Gluconeogenesis during endurance exercise in cyclists habituated to a long-term low carbohydrate high fat diet. J Physiol (Lond) 2016;594:4389-405.

55 Paoli A, Grimaldi K, Bianco A, et al. Medium term effects of a ketogenic diet and a Mediterranean diet on resting energy expenditure and respiratory ratio. BMC Proc 2012:6:P37

56 Hall KD, Bemis T, Brychta R, et al. Calorie for calorie, dietary fat restriction results in more body fat loss than carbohydrate restriction in people with obesity. Cell Metab 2015;22:427-36.

57 Cersosimo E, Triplitt C, Mandarino LJ, et al. Pathogenesis of type 2 diabetes mellitus. In: De Groot LJ, Beck-Peccoz P, Chrousos G, et al, eds. Endotext. South Dartmouth, MA: MDText.com, 2000.

58 Fabbrini E, Higgins PB, Magkos F, et al. Metabolic response to high-carbohydrate and low-carbohydrate meals in a nonhuman primate model. Am J Physiol Endocrinol Metab 2013;304:E444-51.

59 Allen FM, Stillman E, Fitz R. Total dietary regulation in the treatment of diabetes. No. 11. New York: The Rockerfeller Institute for Medical Research, 1919:1-650.

60 Hamdy 0. Nutrition revolution - the end of the high carbohydrates era for diabetes: prevention and management. US Endocrinol 2014;10:103-4.

61 Schofield G, Henderson G, Thornley S, et al. Very low-carbohydrate diets in the management of diabetes revisited. NZ Med J 2016;129:67-73.

62 Hussain TA, Mathew TC, Dashti AA, et al. Effect of low-calorie versus low-carbohydrate ketogenic diet in type 2 diabetes. Nutrition 2012;28:1016-21.

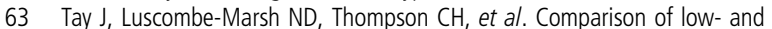
high-carbohydrate diets for type 2 diabetes management: a randomized trial. Am J Clin Nutr 2015;102:780-90.

64 Gannon MC, Nuttall FQ. Control of blood glucose in type 2 diabetes without weight loss by modification of diet composition. Nutr Metab (Lond) 2006;3:16.

65 Guldbrand H, Dizdar B, Bunjaku B, et al. In type 2 diabetes, randomisation to advice to follow a low-carbohydrate diet transiently improves glycaemic control compared with advice to follow a low-fat diet producing a similar weight loss. Diabetologia 2012;55:2118-27.

66 Keys A, Menotti A, Karvonen MJ, et al. The diet and 15-year death rate in the seven countries study. Am J Epidemiol 1986;124:903-15.

67 Harcombe Z, Baker JS, Cooper SM, et al. Evidence from randomised controlled trials did not support the introduction of dietary fat guidelines in 1977 and 1983: a systematic review and meta-analysis. Open Heart 2015;2:e000196.

68 Noakes TD. The 2012 University of Cape Town faculty of health sciences centenary debate. SA J Clin Nutr 2016;28:19-33.

69 Brinkworth GD, Noakes M, Buckley JD, et al. Long-term effects of a very-low-carbohydrate weight loss diet compared with an isocaloric low-fat diet after 12 mo. Am J Clin Nutr 2009;90:23-32.

70 Tay J, Brinkworth GD, Noakes M, et al. Metabolic effects of weight loss on a very-low-carbohydrate diet compared with an isocaloric high-carbohydrate diet in abdominally obese subjects. J Am Coll Cardiol 2008;51:59-67.

71 Keogh JB, Brinkworth GD, Noakes $M$, et al. Effects of weight loss from a verylow-carbohydrate diet on endothelial function and markers of cardiovascular disease risk in subjects with abdominal obesity. Am J Clin Nutr 2008:87:567-76.

72 Volek JS, Fernandez ML, Feinman RD, et al. Dietary carbohydrate restriction induces a unique metabolic state positively affecting atherogenic dyslipidemia, fatty acid partitioning, and metabolic syndrome. Prog Lipid Res 2008;47:307-18.

73 Feinman RD, Volek JS, Westman EC. Dietary carbohydrate restriction in the treatment of diabetes and metabolic syndrome. Clin Nutr Insight 2008;34:5

74 da Luz PL, Favarato D, Faria-Neto JRJ, et al. High ratio of triglycerides to $\mathrm{HDL}$-cholesterol predicts extensive coronary disease. Clinics (Sao Paulo) 2008;63:427-32.

75 Forsythe CE, Phinney SD, Feinman RD, et al. Limited effect of dietary saturated fat on plasma saturated fat in the context of a low carbohydrate diet. Lipids 2010:45:947-62.

76 Dashti HM, Mathew TC, Hussein T, et al. Long-term effects of a ketogenic diet in obese patients. Exp Clin Cardiol 2004;9:200-5.

77 Hernandez TL, Sutherland JP, Wolfe P, et al. Lack of suppression of circulating free fatty acids and hypercholesterolemia during weight loss on a high-fat, low-carbohydrate diet. Am J Clin Nutr 2010;91:578-85.

78 Wood TR, Hansen R, Sigurethsson AF, et al. The cardiovascular risk reduction benefits of a low-carbohydrate diet outweigh the potential increase in LDL-cholesterol. Br J Nutr 2016;115:1126-8.

79 Grieb P, Klapcinska B, Smol E, et al. Long-term consumption of a carbohydrate-restricted diet does not induce deleterious metabolic effects. Nutr Res 2008;28:825-33.

80 Menown IB, Murtagh G, Maher V, et al. Dyslipidemia therapy update: the importance of full lipid profile assessment. Adv Ther 2009;26:711-18.

81 Superko RH. Lipoprotein subclasses and atherosclerosis. Front Biosci 2001;6: D355-65.

82 Boizel R, Benhamou PY, Lardy B, et al. Ratio of triglycerides to HDL cholesterol is an indicator of LDL particle size in patients with type 2 diabetes and normal HDL cholesterol levels. Diabetes Care 2000;23:1679-85. 
83 Lahdenpera S, Syvanne M, Kahri J, et al. Regulation of low-density lipoprotein particle size distribution in NIDDM and coronary disease: importance of serum triglycerides. Diabetologia 1996;39:453-61.

84 Wood RJ, Volek JS, Liu Y, et al. Carbohydrate restriction alters lipoprotein metabolism by modifying VLDL, LDL, and HDL subfraction distribution and size in overweight men. J Nutr 2006;136:384-9.

85 Volek JS, Sharman MJ, Forsythe CE. Modification of lipoproteins by very low-carbohydrate diets. J Nutr 2005;135:1339-42.

86 Sniderman AD, Blank D, Zakarian R, et al. Triglycerides and small dense LDL: the twin Achilles heels of the Friedewald formula. Clin Biochem 2003:36:499-504.

87 Volk BM, Kunces LJ, Freidenreich DJ, et al. Effects of step-wise increases in dietary carbohydrate on circulating saturated fatty acids and palmitoleic acid in adults with metabolic syndrome. PLOS ONE 2014;9:e113605.

88 Targher G, Marra F, Marchesini G. Increased risk of cardiovascular disease in non-alcoholic fatty liver disease: causal effect or epiphenomenon? Diabetologia 2008;51:1947-53.

89 Taskinen MR, Adiels M, Westerbacka J, et al. Dual metabolic defects are required to produce hypertriglyceridemia in obese subjects. Arterioscler Thromb Vasc Biol 2011;31:2144-50.

90 Yki-Jarvinen $\mathrm{H}$. Non-alcoholic fatty liver disease as a cause and a consequence of metabolic syndrome. Lancet Diabetes Endocrinol 2014;2:901-10.

91 Bril F, Lomonaco R, Orsak B, et al. Relationship between disease severity, hyperinsulinemia, and impaired insulin clearance in patients with nonalcoholic steatohepatitis. Hepatology 2014;59:2178-87.

92 Jin ES, Szuszkiewicz-Garcia M, Browning JD, et al. Influence of liver triglycerides on suppression of glucose production by insulin in men. J Clin Endocrinol Metab 2015;100:235-43.

93 Bian $\mathrm{H}$, Hakkarainen A, Lundbom N, et al. Effects of dietary interventions on liver volume in humans. Obesity (Silver Spring) 2014;22:989-95.

94 Neuschwander-Tetri BA. Carbohydrate intake and nonalcoholic fatty liver disease. Curr Opin Clin Nutr Metab Care 2013;16:446-52.

95 Browning JD, Baker JA, Rogers T, et al. Short-term weight loss and hepatic triglyceride reduction: evidence of a metabolic advantage with dietary carbohydrate restriction. Am J Clin Nutr 2011;93:1048-52.

96 Owen OE, Morgan AP, Kemp HG, et al. Brain metabolism during fasting. J Clin Invest 1967;46:1589-95.

97 Paoli A, Rubini A, Volek JS, et al. Beyond weight loss: a review of the therapeutic uses of very-low-carbohydrate (ketogenic) diets. Eur J Clin Nutr 2013;67:789-96.

98 Medina JM, Tabernero A. Lactate utilization by brain cells and its role in CNS development. J Neurosci Res 2005;79:2-10.

99 Mitchell GA, Kassovska-Bratinova S, Boukaftane $Y$, et al. Medical aspects of ketone body metabolism. Clin Invest Med 1995;18:193-216.

100 Cox PJ, Clarke K. Acute nutritional ketosis: implications for exercise performance and metabolism. Extrem Physiol Med 2014;3:17.

101 Cox PJ, Kirk T, Ashmore T, et al. Nutritional ketosis alters fuel preference and thereby endurance performance in athletes. Cell Metab 2016;24:256-68.

102 Larosa JC, Fry AG, Muesing R, et al. Effects of high-protein, low-carbohydrate dieting on plasma lipoproteins and body weight. J Am Diet Assoc 1980;77:264-70.

103 Siri-Tarino PW, Sun Q, Hu FB, et al. Meta-analysis of prospective cohort studies evaluating the association of saturated fat with cardiovascular disease. Am J Clin Nutr 2010:91:535-46.

104 Hooper L, Summerbell CD, Thompson R, et al. Reduced or modified dietary fat for preventing cardiovascular disease. Cochrane Database Syst Rev 2012;(5):CD002137.

105 Hooper L, Summerbell CD, Thompson R, et al. Reduced or modified dietary fat for preventing cardiovascular disease. Cochrane Database Syst Rev 2011;(7): CD002137.

106 Skeaff CM, Miller J. Dietary fat and coronary heart disease: summary of evidence from prospective cohort and randomised controlled trials. Ann Nutr Metab 2009;55:173-201.

107 Jakobsen MU, O'Reilly EJ, Heitmann BL, et al. Major types of dietary fat and risk of coronary heart disease: a pooled analysis of 11 cohort studies. Am J Clin Nutr 2009:89:1425-32.

108 De Souza RJ, Mente A, Maroleanu A, et al. Intake of saturated and trans unsaturated fatty acids and risk of all cause mortality, cardiovascular disease, and type 2 diabetes: systematic review and meta-analysis of observational studies. BMJ 2015;351:h3978.

109 Praagman J, Beulens JW, Alssema M, et al. The association between dietary saturated fatty acids and ischemic heart disease depends on the type and source of fatty acid in the European Prospective Investigation into Cancer and Nutrition-Netherlands cohort. Am J Clin Nutr 2016;103:356-65.

110 Mente A, De Koning L, Shannon HS, et al. A systematic review of the evidence supporting a causal link between dietary factors and coronary heart disease. Arch Intern Med 2009;169:659-69.

111 Chowdhury R, Warnakula S, Kunutsor S, et al. Association of dietary, circulating, and supplement fatty acids with coronary risk: a systematic review and meta-analysis. Ann Intern Med 2014;160:398-406.

112 Puaschitz NG, Strand E, Norekval TM, et al. Dietary intake of saturated fat is not associated with risk of coronary events or mortality in patients with established coronary artery disease. J Nutr 2015;145:299-305.

113 Schoenaker DA, Toeller M, Chaturvedi N, et al. Dietary saturated fat and fibre and risk of cardiovascular disease and all-cause mortality among type 1 diabetic patients: the EURODIAB Prospective Complications Study. Diabetologia 2012;55:2132-41.

114 Mozaffarian D, Rimm EB, Herrington DM. Dietary fats, carbohydrate, and progression of coronary atherosclerosis in postmenopausal women. Am J Clin Nutr 2004;80:1175-84

115 Gillman MW, Cupples LA, Millen BE, et al. Inverse association of dietary fat with development of ischemic stroke in men. JAMA 1997;278:2145-50.

116 Sekikawa A, Miyamoto Y, Miura K, et al. Continuous decline in mortality from coronary heart disease in Japan despite a continuous and marked rise in total cholesterol: Japanese experience after the Seven Countries Study. Int J Epidemiol 2015:44:1614-24.

117 Credit Suisse. Fat: the new health paradigm. Research Institute, 2015:1-73.

118 Harcombe Z, Baker JS. Plant sterols lower cholesterol, but increase risk for coronary heart disease. Online J Biol Sci 2016;14:167-9.

119 DiNicolantonio JJ. The cardiometabolic consequences of replacing saturated fats with carbohydrates or omega- 6 polyunsaturated fats: do the dietary guidelines have it wrong? Open Heart 2014;1:1-4.

120 Ravnskov U, DiNicolantonio JJ, Harcombe Z, et al. The questionable benefits of exchanging saturated fat with polyunsaturated fat. Mayo Clin Proc 2014:89:451-3.

121 Ramsden CE, Zamora D, Leelarthaepin B, et al. Use of dietary linoleic acid for secondary prevention of coronary heart disease and death: evaluation of recovered data from the Sydney Diet Heart Study and updated meta-analysis. BMJ 2013;346: e8707.

122 Ramsden CE, Zamora D, Majchrzak-Hong S, et al. Re-evaluation of the traditional diet-heart hypothesis: analysis of recovered data from Minnesota Coronary Experiment (1968-73). BMJ 2016;353:11246.

123 Shapira N. Israeli 'cancer shift' over heart disease mortality may be led by greater risk in women with high intake of n-6 fatty acids. Eur J Cancer Prev 2007:16:486-94.

124 Aykan NF. Red meat and colorectal cancer. Oncol Rev 2015:9:288.

125 Chan DS, Lau R, Aune D, et al. Red and processed meat and colorectal cancer incidence: meta-analysis of prospective studies. PLOS ONE 2011;6:e20456.

126 Cho E, Smith-Warner A. Meat and fat intake and colorectal cancer risk: a pooled analysis of 14 prospective studies. Cancer Res 2004;64:113.

127 Binnie MA, Barlow K, Johnson V, et al. Red meats: time for a paradigm shift in dietary advice. Meat Sci 2014;98:445-51.

128 O'Connor LE, Kim JE, Campbell WW. Consuming $<$ or $>0.5$ servings of red meat per day does not have a negative impact on cardiovascular disease risk factors; a systematic review and meta-analysis of randomized controlled trials. FASEB $\lrcorner$ 2016;30:\$904.1.

129 Martin WF, Armstrong LE, Rodriguez NR. Dietary protein intake and renal function. Nutr Metab (Lond) 2005;2:25

130 Pecoits-Filho R. Dietary protein intake and kidney disease in Western diet. Contrib Nephrol 2007;155:102-12.

131 Tay J, Thompson CH, Luscombe-Marsh ND, et al. Long-term effects of a very low carbohydrate compared with a high carbohydrate diet on renal function in individuals with type 2 diabetes: a randomized trial. Medicine (Baltimore) 2015;94:e2181.

132 Westman EC, Feinman RD, Mavropoulos JC, et al. Low-carbohydrate nutrition and metabolism. Am J Clin Nutr 2007;86:276-84.

133 Feinman RD, Vernon MC, Westman EC. Low carbohydrate diets in family practice: what can we learn from an internet-based support group. Nutr J 2006;5:26.

134 Yang MU, Van Itallie TB. Composition of weight lost during short-term weight reduction. Metabolic responses of obese subjects to starvation and low-calorie ketogenic and nonketogenic diets. J Clin Invest 1976;58:722-30. 